\title{
COMMUNICATION
}

Cite this: DOI: $10.1039 /$ xoxxooooox

Received ooth January 2012,

Accepted ooth January 2012

DOI: 10.1039/xoxxooooox

www.rsc.org/

\section{Furanosic forms of sugars: Conformational equilibrium of methyl $\beta$-D-ribofuranoside}

\author{
Patricia Écija, ${ }^{a}$ Iciar Uriarte, ${ }^{a}$ Lorenzo Spada,${ }^{a, b}$ Benjamin G. Davis, ${ }^{c}$ Walther \\ Caminati, ${ }^{\text {b }}$ Francisco J. Basterretxea, ${ }^{a}$ Alberto Lesarri, ${ }^{* d}$ Emilio J. Cocinero*a
}

This is the first investigation of an isolated ribofuranose unit in the gas phase, revealing the intrinsic conformational landscape of the biologically active sugar form. We report the rotational spectra of two conformers of methyl $\beta$-Dribofuranoside in a supersonic jet expansion. Both conformers adopt a twisted $\left({ }^{3} T_{2}\right)$ ring conformation with the methoxy and hydroxymethyl substituents involved in various intramolecular hydrogen bonds.

Sugars are flexible polymorphic species, exhibiting complex constitutional, configurational and conformational isomerism. The intramolecular reaction between carbonyl (typically reducing terminus) and hydroxyl groups gives rise to cyclic hemiacetal $/$ ketals, particularly stable for five- or six-membered ring forms (furanose or pyranose, respectively, Scheme 1). Large amplitude motions, like ring puckering, inversion or pseudorotation, combine with the internal rotation of the hydroxyl groups to produce a very rich conformational landscape, even in the most elementary monosaccharide units. A recent microwave spectroscopy study on ribose proved that this aldopentose is a pyranose (1) in the gasphase, with six coexisting low-energy $\left(\Delta E<6 \mathrm{~kJ} \mathrm{~mol}^{-1}\right)$ conformers differing in ring conformation $\left({ }^{1} \mathrm{C}_{4}\right.$ or $\left.{ }^{4} \mathrm{C}_{1}\right)$ and epimerization $(\alpha / \beta) .{ }^{1}$ Other rotational ${ }^{2}$ and vibrational ${ }^{3}$ studies of five- or six-carbon monosaccharides have also confirmed the pyranose preference of free molecules, which had also been previously observed in the crystal $^{4,5}$ and liquid phases. ${ }^{6}$ However, the preferred ribopyranose form starkly contrasts with the biological use of five-membered $\beta$ ribofuranose rings (2).

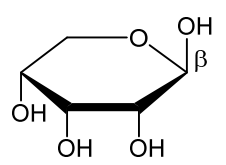

(1)

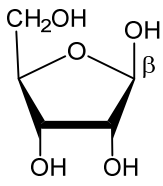

(2)

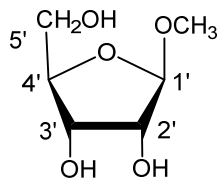

(3)
Scheme 1. The pyranose (1) and furanose (2) constitutional isomers of ribose together with methyl- $\beta$-D-ribofuranoside (3), all shown as Haworth representations.
Ribofuranoside rings are present in a number of locations in Biology. In most species they appear as informational molecules and catalysts in RNA, as substrates such as ATP or sugar-diphosphonucleosides, or cofactors such as $\mathrm{NAD}(\mathrm{P})$ or $\mathrm{NAD}(\mathrm{P}) \mathrm{H} .{ }^{7}$ Remarkably, their roles are often critical: DNA analogues in which the furanose rings are exchanged by pyranoses produce double helices with much stronger base pairing but they cannot replace DNA biologically. ${ }^{8}$ These observations indicate that biochemical functionality in ribose-based biomolecules relies on multiply related factors and that functional optimization does not necessarily correlate with simple properties in the ground state (such as individual pairing strength). Changes in furanose conformation can also critically modulate the ability of nucleosides to act as substrates with diverse enzymes vital to associated processes of relevance to disease, e.g. HIV-1 reverse transcriptase. ${ }^{9}$ Various furanosides also appear as part of oligosaccharides in plants and microbial organisms like bacteria, fungi and parasites, although interestingly not in humans or in mammals. ${ }^{10}$

Ultimately, the evolutionary preference for furanoses in RNA and other biomolecules may have a chemical origin, associated perhaps with the greater or differing flexibility of the five-membered ring. Saturated five-membered rings are structurally unique, as the small differences in energy between twisted and envelope forms give rise to pseudorotation, a quasi-monodimensional large-amplitudemotion in which puckering rotates around the ring. ${ }^{11}$ Furanose ringpuckered species thus interconvert without passing through planar species, making it difficult to specify conformational properties and pseudorotation pathways. A first pseudorotation model for nucleosides was developed by Altona and Sundaralingam (AS). ${ }^{12}$ Cremer and Pople (CP) later solved the puckering problem using vibrational analysis and developed systematic curvilinear $\mathrm{CP}$ coordinates, ${ }^{13}$ generally applicable to any cycloalkane. Both models define furanoside puckering in terms of amplitude $(q)$ and phase coordinates ( $\varphi_{\mathrm{AS}}$ and $\varphi_{\mathrm{CP}}$ phase conventions are shifted by a constant angle). Noticeably, a first survey of crystal structures revealed that furanoside conformations in nucleosides display a bimodal distribution, ${ }^{14}$ with two preferred puckering regions around $\varphi_{\mathrm{CP}}=288^{\circ}$ $\left(\varphi_{A S}=18^{\circ} \text {, envelope }{ }^{3} \mathrm{E} \equiv \mathrm{C}_{3^{\prime}}{ }^{\prime} \text {-endo }\right)^{15}$ or $\varphi_{\mathrm{CP}}=72^{\circ}\left(\varphi_{\mathrm{AS}}=162^{\circ}\right.$, envelope ${ }^{2} \mathrm{E} \equiv \mathrm{C}_{2}{ }^{\prime}$-endo). This two-state model has been instrumental for puckering determination in solution using NMR vicinal spin-spin coupling parameters. ${ }^{16}$ More recent structural investigations on 
furanose glycosides showed similar clustering in conformational space, but heavily dependent on the pentose configuration. ${ }^{10}$ In particular, $\beta$-ribofuranosides locate around puckering phases of $\varphi{ }_{C P}=252^{\circ}$ (envelope $E_{2}$ ) in the solid state. Recurrently, the question thus arises: does the furanose conformation in the crystal or solution reflect intrinsic ring puckering properties, or is it imposed by the environment?

We answer this question by exploring the molecular structure of the five-membered ring unit of an isolated monosaccharide in the gas-phase. We analyzed methyl $\beta$-D-ribofuranoside (3, Scheme 1) using a combination of chemical synthesis, microwave spectroscopy, supersonic jet expansion techniques, ultrafast laser vaporization and computational methods. The target pentose was specifically synthesized (see ESI) to lock the molecule as a five-membered ring, preventing the formation of the pyranose form dominant in gas phase. Our main objectives include the first observation of conformational preferences of furanose forms in C5 and C6 sugars, the determination of the number of coexisting species for the free molecule, and the comparison with the structural data in condensed phases. The conformational landscape was explored at different levels, including ring-puckering preferences, dynamics of the hydroxyl and hydroxymethyl groups, intramolecular hydrogen bonding and internal rotation of the methyl group. Our results give a valuable perspective on the intrinsic structural preferences of this biologically important aldopentofuranose, clarifying previous X-ray and neutron diffraction, ${ }^{17} \mathrm{NMR}^{18}$ and $a b$ initio data. ${ }^{19}$

The computational study included a comprehensive conformational search combining molecular mechanics (MMFFs) and special search algorithms based on stochastic and vibrational mode analysis, ${ }^{20}$ together with $a b$ initio (MP2) and densityfunctional-theory (M06-2X, B3LYP) molecular orbital reoptimizations, which refined the initial estimations. The final conformational energies are in Table S1, while Table 1 gives the results for the six conformers with energies within $5 \mathrm{~kJ} \mathrm{~mol}^{-1}$.

Table 1: Prediction of conformational energies for methyl $\beta$-D-ribofuranose.

\begin{tabular}{ccccccc}
\hline Species $^{\mathrm{a}}$ & $\Delta \mathrm{G}^{\mathrm{b}} / \mathrm{kJ} \mathrm{mol}^{-1}$ & $\begin{array}{c}q / \\
\AA^{\mathrm{c}}\end{array}$ & $\begin{array}{c}\varphi / \\
\mathrm{deg}\end{array}$ & $\begin{array}{c}\mu_{\mathrm{a}} / \\
\mathrm{D}^{\mathrm{d}}\end{array}$ & $\begin{array}{c}\mu_{\mathrm{b}} / \\
\mathrm{D}\end{array}$ & $\begin{array}{c}\mu_{\mathrm{c}} / \\
\mathrm{D}\end{array}$ \\
\hline $1\left({ }^{3} \mathrm{~T}_{2}\right)$ & $0.0 / 0.0 / 0.0$ & 0.385 & 264.7 & 0.0 & -0.3 & -1.2 \\
$2\left({ }^{3} \mathrm{~T}_{2}\right)$ & $0.8 / 1.2 / 0.9$ & 0.397 & 260.7 & -0.9 & -3.5 & -0.9 \\
$3\left({ }^{3} \mathrm{~T}_{2}\right)$ & $2.9 / 0.4 / 2.2$ & 0.397 & 266.4 & -1.6 & -3.5 & 1.7 \\
$4\left(\mathrm{E}_{2}\right)$ & $3.5 / 4.6 / 2.9$ & 0.400 & 252.3 & 1.3 & -4.1 & 0.7 \\
$5\left({ }^{2} \mathrm{E}\right)$ & $3.7 / 2.0 / 1.5$ & 0.382 & 62.7 & -2.1 & -0.3 & -0.5 \\
$6\left(\mathrm{E}_{2}\right)$ & $4.9 / 5.0 / 3.6$ & 0.391 & 247.8 & -0.9 & -1.4 & 2.9
\end{tabular}

a Conformational notation in 15. ' ${ }^{\mathrm{D}} \mathrm{MP} 2 / \mathrm{M} 06-2 \mathrm{X} / \mathrm{B} 3 \mathrm{LYP}$ calculations with a 6 $311++G(d, p)$ basis set; Relative Gibbs free energies at $298 \mathrm{~K} .{ }^{\circ}$ Cremer-Pople puckering parameters in $13 .{ }^{d}$ Electric dipole moment components $\left(\mu_{\mathrm{a}}, \mu_{\mathrm{b}}, \mu_{\mathrm{c}}\right)$.

The calculated conformational stabilities were checked against the experimental microwave spectrum in the $6-14 \mathrm{GHz}$ frequency region. The molecular jet was probed with a Fourier-transform microwave (FT-MW) spectrometer equipped with an UV ultrafast laser vaporization system, ${ }^{1}$ details are given in the ESI (section 2). Two different sets of rotational transitions were independently assigned (Figure 1). The first set was composed exclusively of $R$ branch $(J+1 \leftarrow J) \quad \mu_{\mathrm{c}}$-type transitions, with angular momentum quantum numbers spanning $J=2-6$. The second set included only $R$ branch $\mu_{\mathrm{b}}$-type rotational transitions $(J=2-7)$. Both datasets were mutually exclusive and they clearly corresponded to two different carrier species. The similarity in rotational constants suggested that they are indeed isomers of the same molecule. Some of the observed lines showed small hyperfine effects for the two species, splitting some individual transitions into two close components separated by less than $20 \mathrm{kHz}$.

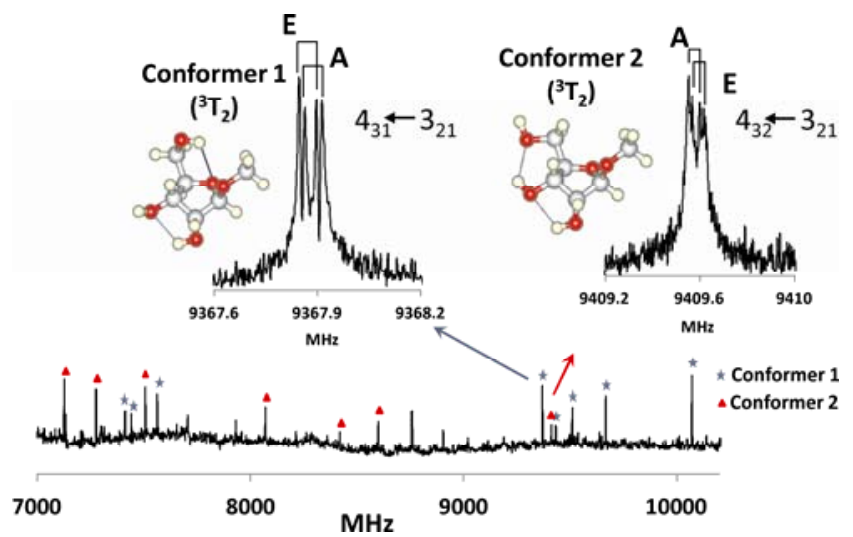

Fig. $1 \mathrm{~A}$ section of the experimental spectrum of methyl $\beta$-D-ribofuranoside in the region $7-10 \mathrm{GHz}$, together with two example rotational transitions split by internal rotation of the methyl group.

The hyperfine effects were attributed to the internal rotation of the $O-1$ methyl group in the ribofuranoside, detectable in rotational spectra for small or moderate potential energy barriers. ${ }^{21}$ The experimental observations were reproduced to experimental accuracy with a semirigid-rotor Watson Hamiltonian (S-reduction). ${ }^{22}$ The internal rotation effects were analyzed with the Wood's internalaxis-method (IAM) method. ${ }^{23}$ Table 2 presents the results of leastsquares fits of the experimental transitions of both conformers, which yielded accurate values of the rotational constants, the quartic centrifugal distortion constants and the internal rotation barrier height. The full set of transitions is collected in Tables S2 and S3. No lines attributable to other conformers were observed in the spectrum.

Table 2: Experimental parameters for the two detected conformations of methyl $\beta$-D-ribofuranoside, and comparison with the MP2 predictions.

\begin{tabular}{|c|c|c|c|c|}
\hline & \multicolumn{2}{|c|}{ Conf. 1} & \multicolumn{2}{|c|}{ Conf. 2} \\
\hline & Experiment & Theory & Experiment & Theory \\
\hline $\mathrm{A} / \mathrm{MHz}$ & $1307.1463(55)^{\mathrm{a}}$ & 1295.21 & $1443.5094(14)$ & 1438.72 \\
\hline $\mathrm{B} / \mathrm{MHz}$ & $1095.47128(50)$ & 1101.10 & $924.98477(53)$ & 943.70 \\
\hline $\mathrm{C} / \mathrm{MHz}$ & $717.8046(49)$ & 718.90 & $661.97710(32)$ & 674.86 \\
\hline$D_{\mathrm{J}} / \mathrm{kHz}$ & $0.953(81)$ & & $0.2752(48)$ & \\
\hline$D_{\mathrm{JK}} / \mathrm{kHz}$ & $-0.339(88)$ & & $-1.264(27)$ & \\
\hline$D_{\mathrm{K}} / \mathrm{kHz}$ & & & $1.702(97)$ & \\
\hline$d_{1} / \mathrm{Hz}$ & $0.723(66)$ & & $-0.1004(31)$ & \\
\hline$d_{2} / \mathrm{Hz}$ & $-0.277(24)$ & & & \\
\hline$V_{3}{ }^{\mathrm{b}} / \mathrm{kJ} \mathrm{mol}^{-1}$ & $7.304(13)$ & 7.90 & $7.503(64)$ & 8.23 \\
\hline$\sigma / \mathrm{kHz}^{\mathrm{c}}$ & 4.7 & & 3.0 & \\
\hline$N^{\mathrm{d}}$ & 46 & & 32 & \\
\hline
\end{tabular}

aUncertainties in units of the last digit. 'Internal rotation barrier. The geometrical parameters $I_{\alpha}\left(=3.195 u \AA^{2}\right)$ and $<(i, a),<(i, b),<(i, c)\left(=23.1^{\circ}, 81.3^{\circ}, 68.8^{\circ}, 51.4^{\circ}\right.$ $43.9^{\circ}$ and $72.3^{\circ}$, respectively, for conformers 1 and 2 ) have been fixed to the $a b$ initio values. "Standard deviation of the fit. ${ }^{\mathrm{d}}$ Number of transitions.

The conformational assignment of the two isomers relied on multiple arguments. An initial comparison of the rotational constants in Table 2 showed good agreement for the two lowest-lying conformations (relative errors below $1 \%$ for the global minimum, $<$ $2 \%$ for the second conformer). The prediction of (harmonic) centrifugal distortion constants was also consistent in magnitude and sign with the proposed assignment. Finally, the methyl group $V_{3}$ barrier increase for conformer $2\left(V_{3}=7.3\right.$ vs. $\left.7.5 \mathrm{~kJ} \mathrm{~mol}^{-1}\right)$ is in agreement with the $a b$ initio predictions $\left(7.9 \mathrm{vs} .8 .2 \mathrm{~kJ} \mathrm{~mol}^{-1}\right)$. This 


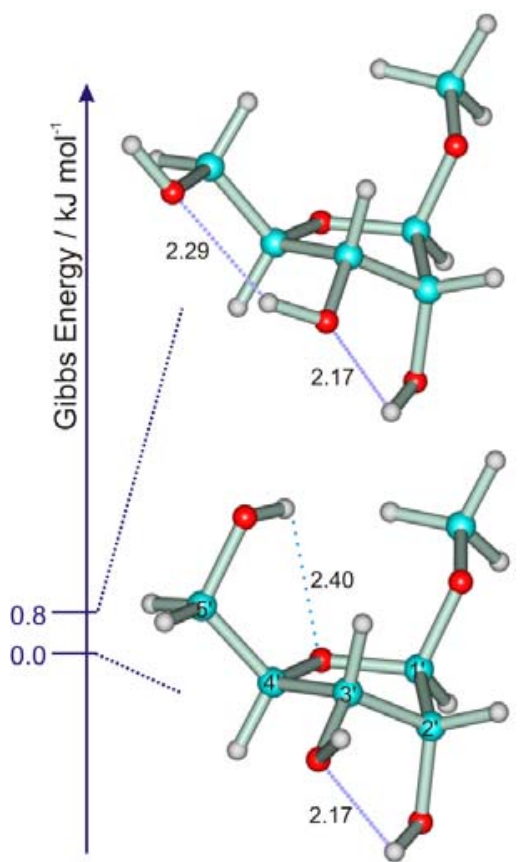

Fig. 2 Intramolecular hydrogen bonding distances $(\AA)$ and relative Gibbs energy (MP2) for the two observed conformers of methyl $\beta$-D-ribofuranose.

evidence fully confirms the conformational assignments in Table 2 and Figure 2 (see the interactive 3D model in the ESI, section 5).

The ring-puckering properties were analyzed quantitatively, using the $\mathrm{CP}$ coordinates ${ }^{13}$ in Figure 3 . The two detected isomers have similar puckering phases $\left(\varphi_{\mathrm{C} P}=264.7^{\circ}\right.$ and $260.7^{\circ}$, respectively $)$, intermediate between a twisted- ${ }^{3} \mathrm{~T}_{2}$ and an envelope- $\mathrm{E}_{2}$ ring conformation. Puckering amplitudes are also very similar $(q=0.385$ and $0.397 \AA$, respectively). The hydroxymethyl side chain adopts the gauche staggered orientation of Scheme 2, either $\mathrm{G}^{+}\left(\tau_{1}\left(\mathrm{O}_{5^{\prime}}-\mathrm{C}_{5^{\prime}}-\mathrm{C}_{4^{\prime}-}\right.\right.$ $\left.\left.\mathrm{C}_{3^{\prime}}\right)=+56.2^{\circ}\right)$ for the global minimum or $\mathrm{G}^{-}\left(\tau_{1}=-58.1^{\circ}\right)$ for the second conformer. Conversely, the methyl group is always trans with respect to $\mathrm{C}_{2}{ }^{\prime}\left(\mathrm{T}\right.$ : $\tau_{2}\left(\mathrm{C}_{\mathrm{M}}-\mathrm{O}_{1^{\prime}}{ }^{\prime} \mathrm{C}_{1^{\prime}-\mathrm{C}_{2}}\right)=174.4^{\circ}$ and $178.9^{\circ}$, respectively), so the observed conformations are denoted ${ }^{3} \mathrm{~T}_{2} \mathrm{G}^{+} \mathrm{T}$ (global minimum) and ${ }^{3} \mathrm{~T}_{2} \mathrm{G}^{-} \mathrm{T}$.<smiles>CO[C@H]1[C@@H]2[CH][CH][C@@H](O2)[C@H]1OC</smiles>

G+

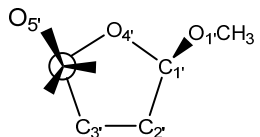

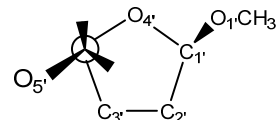

G-
Scheme 2 Notation for staggered orientations around the $\mathrm{C}_{4^{\prime}}-\mathrm{C}_{5^{\prime}}$ bond.

The two ring hydroxyl groups, on opposite sides of the methoxy and hydroxymethyl substituents, finally arrange to reach the highest possible number of internal hydrogen bonds. The global minimum exhibits two unconnected hydrogen bonds: a weak contact $\mathrm{O}_{5}{ }^{\prime}-$ $\mathrm{H}^{\cdots} \mathrm{O}_{4^{\prime}}$ with the hydroxymethyl group (MP2: $\left.\mathrm{r}\left(\mathrm{H}^{\cdots} \mathrm{O}_{4}{ }^{\prime}\right)=2.4 \AA\right)$ and a $\mathrm{O}_{2}{ }^{\prime}-\mathrm{H}^{\cdots} \mathrm{O}_{3^{\prime}}$ link (MP2: $\mathrm{r}\left(\mathrm{H}^{\cdots} \mathrm{O}_{3^{\prime}}\right)=2.17 \AA$ ). The second conformer displays a network of two successive $\mathrm{O}_{2}-\mathrm{H}^{\prime} \cdots \mathrm{O}_{3}-\mathrm{H}^{\prime} \cdots \mathrm{O}_{5^{\prime}}$ hydrogen bonds involving three hydroxyl groups (MP2: $\mathrm{r}\left(\mathrm{H}^{\cdots} \mathrm{O}_{3^{\prime}}{ }^{\prime}\right)=2.17 \AA$, $\left.\mathrm{r}\left(\mathrm{H}^{\cdots} \mathrm{O}_{5^{\prime}}\right)=2.29 \AA\right)$

In conclusion, the combination of rotational data and $a b$ initio calculations provides a direct comparison between $\beta$-ribofuranoside ring conformations in the gas phase and crystal structures. The isolated molecule preferably occupies three regions of the
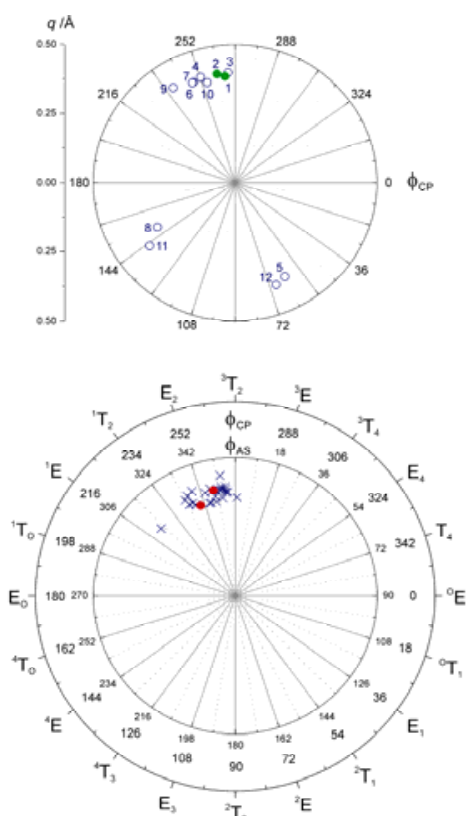

Fig. 3 Comparison of the conformational landscape of the $\beta$-ribofuranoside ring in the gas phase and crystal structures. a) Upper panel: Results of the ab initio conformational search for methyl $\beta$-D-ribofuranoside (twelve most stable structures; experimental conformers with green solid circles). b) Lower panel: A survey of 30 fragment structures of furanose glycosides in the Cambridge Structural Database (CSD, data from ref. 10, blue crosses), together with the 2 crystal structures of methyl $\beta$-D-ribofuranoside observed by neutron diffraction in (ref. 17, red circles). Cremer-Pople (CP) puckering amplitudes $(q)$ represented as radial values. Pseudorotation angles given in the $\mathrm{CP}\left(\varphi_{\mathrm{CP}}\right)$ and AltonaSundaralingan (AS) conventions $\left(\varphi_{\mathrm{AS}}\right)$. Conformer notation in ref. 15.

conformational space, represented by the ${ }^{3} \mathrm{~T}_{2}-\mathrm{E}_{2},{ }^{2} \mathrm{E}$ and ${ }^{4} \mathrm{E}$ structures in Figure 3.

The three most stable structures $\left(<3 \mathrm{~kJ} \mathrm{~mol}^{-1}\right)$ share a twisted ${ }^{3} \mathrm{~T}_{2}$ and envelope $\mathrm{E}_{2}$ character, but most of the following conformations up to ca. $8 \mathrm{~kJ} \mathrm{~mol}^{-1}$ move toward the neighboring envelope $\mathrm{E}_{2}$. The higher-energy forms of the isolated molecule comprise also envelopes ${ }^{2} \mathrm{E}$ and ${ }^{4} \mathrm{E}$, which appear at relative energies above 3.7 and $7.3 \mathrm{~kJ} \mathrm{~mol}^{-1}$ (MP2), respectively, and become the most abundant in the upper range of the analyzed energy window. The two observed conformations for the isolated molecule simply represent alternative configurations of the sugar hydroxymethyl side-chain (the third conformer being equivalent to the global minimum with reversed $\mathrm{O}_{3}{ }^{\prime}-\mathrm{H}^{\cdots} \mathrm{O}_{2}$ ' hydrogen bond orientation). In previous rotational studies it was argued that intramolecular hydrogen bonding is the primarily stabilizing effect in isolated monosaccharides. ${ }^{1,2}$ In methyl $\beta$-D-ribofuranoside the hydrogen bond pattern seems to favor conformer 2, predicted only $0.8 \mathrm{~kJ} \mathrm{~mol}^{-1}$ (MP2) to $1.2 \mathrm{~kJ} \mathrm{~mol}^{-1}$ (M06-2X) above the global minimum. However, the predicted stability could also reflect other contributions, like hyperconjugative effects, previously suggested in tetrahydrofuran ${ }^{24}$ and other monosaccharides. Unfortunately, the small energy difference between both conformations cannot be verified experimentally, as the lack of common selection rules precludes estimating intensity ratios. Noticeably, the neutron diffraction experiments of methyl $\beta$ D-ribofuranoside also identified two conformations with $\mathrm{E}_{2}$ ringpuckering $\left(\varphi_{\mathrm{C} P}=258.6^{\circ}, 249.6^{\circ}\right)$, relatively close to the ${ }^{3} \mathrm{~T}_{2}-\mathrm{E}_{2}$ structures observed here. ${ }^{17}$ The two observed crystal structures mostly differ in the orientation of the ring substituents, which are both oriented trans to favor intermolecular hydrogen bonding, concomitant with this condensed phase. No intramolecular hydrogen bond is apparent in the crystal structures.

The comparison between the conformational behavior of an isolated unit of methyl $\beta$-D-ribofuranoside and that of the molecule 
embedded in a crystal matrix reveals features of the factors affecting molecular structure. The ring puckering characteristics of the ribofuranose unit are very similar in the gas and crystal phases, and clearly suggest that the puckering forces associated with the minimization of ring strain originate from the ring configuration and number and position of substitutents, not from crystal forces. This argument is reinforced by comparison with the puckering characteristics of a set of 30 structural fragments in the Cambridge Structural Database (CSD), shown in the lower panel of Figure 3, similarly centered around $\mathrm{E}_{2}$. Furthermore, crystal data show that a change in the substituents' stereochemistry radically alters the ring puckering. ${ }^{10}$ This view is confirmed by previous NMR studies, emphasizing the dominant influence of the anomeric substituent on the ring conformation in liquid phase. ${ }^{25}$ The ring stability would thus result from a subtle balance of molecular orbital effects and/or stereoelectronic effects, difficult to establish a priori. As a consequence, the presence of the heterocyclic bases found in nucleosides surely influences the conformational properties of the flexible ring, thereby determining its final biological properties.

The results for methyl $\beta$-D-ribofuranoside highlight the value of current crystal structures but also call for additional gas-phase experiments on related furanosides, nucleosides and nucleotides, both to assess the theoretical models and to compare with conventional data from condensed media. Considering the vital role of ribofuranosides in all life forms, it is remarkable that their structural properties free of any environmental effects have been unknown until now. These new results provide empirical data that may help to inform structural, predictive and enzymological RNA (and DNA) biology. In this sense, the emergence of new techniques in rotational spectroscopy is helping to provide a global view of the inherent structural properties of these biomolecular building blocks.

\section{Notes and references}

a Departamento de Química Física, Facultad de Ciencia y Tecnología, Universidad del País Vasco (UPV/EHU), Apartado 644, 48080 Bilbao (Spain),emiliojose.cocinero@ehu.eus

b Dipartimento di Chimica "G. Ciamician", Università di Bologna, Via Selmi 2, 1-40126 Bologna (Italy)

c Chemistry Department, Oxford University, Chemistry Research Laboratory, 12 Mansfield Road, OX1 3TA Oxford (United Kingdom)

${ }^{d}$ Departamento de Química Física y Química Inorgánica, Universidad de Valladolid, 47011 Valladolid (Spain), lesarri@qf.uva.es

Electronic Supplementary Information (ESI) available: Rotational transitions and theoretical predictions. See DOI: 10.1039/c000000x/

1 E. J. Cocinero, A. Lesarri, P. Ecija, F. J. Basterretxea, J.-U. Grabow, J. A. Fernández, F. Castaño, Angew. Chem. Int. Ed., 2012, 51, 3119.

2 E.J. Cocinero, A. Lesarri, P. Écija, A. Cimas, B. G. Davis, F. J. Basterretxea, J. A.Fernández, F. Castaño, J. Am. Chem. Soc., 2013, 135, 2845; I. Peña, E. J. Cocinero, C. Cabezas, A. Lesarri, S. Mata, P. Ecija, A. M. Daly, A. Cimas, C. Bermúdez, F. J. Basterretxea, S. Blanco, J. A. Fernández, J. C. Lopez, F. Castaño, J. L. Alonso, Angew. Chem. Int. Ed., 2013, 52, 11840; J. L. Alonso, M. A. Lozoya, I. Peña, J. C. López, C. Cabezas, S. Mata, S. Blanco, Chem. Sci., 2014, 5, 515; I. Peña, C. Cabezas, J. L. Alonso, Angew. Chem. Int. Ed., 2015, 54, 2991.
3 E. J. Cocinero, P. Çarçabal, Spectroscopy and Structure of Biological Molecules; A. M. Rijs, J. Oomens, Ed.; Springer: New York, 2015; pp. 299-333; J. P. Simons, Mol. Phys., 2009, 107, 2435.

4 D. Šišak, L. B McCusker, G. Zandomeneghi, B. H. Meier, D. Bläser, R. Boese, W. B. Schweizer, R. Gilmour, J. D. Dunitz, Angew. Chem. Int. Ed. 2010, 49, 4503.

5 M. Sundaralingam, Biopol. 1969, 7, 821.

6 E. Breitmaier, U. Hollstein, Org. Magn. Reson. 1976, 8, 573; S. J. Angyal, Angew. Chem. 1969, 8, 157; K. N. Drew, J. Zajicek, G. Bondo, B. Bose, A. Serianni, S. Carbohyd. Res. 1998, 307, 199.

7 W. Saenger, Principles of Nucleic Acid Structure; Springer-Verlag: New York, 1984.

8 A. Eschenmoser, Science, 1999, 284, 2118.

9 H. Ford, Jr., F. Dai, L. Mu, M. A. Siddiqui, M. C. Nicklaus, L. Anderson, V. E. Marquez, J. J. Barchi, Biochem., 2000, 39, 2581; V. E. Marquez, P. Wang, M. C. Nicklaus, M. Maiera, M. Manoharana, J. K. Christmanb, N. K. Banavalic, A. D. Mackerell, Jr. Nucleos. Nucleot. Nucl., 2001, 20, 451 and references therein.

10 H. A. Taha, M. R. Richards, T. L. Lowary, Chem. Rev., 2013, 113, 1851.

11 J. Laane, Vibrational Spectra and Structure; J. R. Durig, Ed.; Marcel Dekker, Inc.: New York, 1972; pp. 26-50.

12 C. Altona, M. Sundaralingam, J. Am. Chem. Soc., 1972, 94, 8205.

13 D. Cremer, J. A. Pople, J. Am. Chem. Soc., 1975, 97, 1354.

14 H. P. M. de Leeuw, C. A. G. Haasnoot, C. Altona, Isr. J. Chem., 1980, 20, 108.

15 Notation for ring puckering conformation described in 10 and Eur. J. Biochem., 1980, 111, 295; Pure Appl. Chem., 1981, 53, 1901. The primed atom notation used in nucleosides is adopted for simplicity.

16 F. de Leeuw, C. Altona, J. Comp. Chem., 1983, 4, 428; Z. Dzakula, M. DeRider, J. L. Markley, J. Am. Chem. Soc., 1996, 118, 12796.

17 A. G. Evdokimov, A. J. K. Gilboa, T. F. Koetzle, W. T. Klooster, A. J. Schultz, S. A. Mason, A. Albinati, F. Frolow, Acta Crystallogr. B, 2001, 57, 213; A. G. Evdokimov, A. J. K. Gilboa, T. F. Koetzle, W. T. Klooster, J. M. L. Martin, J. Phys. Chem. A, 1999, 103, 744.

18 J. B. Houseknecht, C. M. Hadad, T. L. Lowary, I. Karplus. J. Phys. Chem. A, 2003, 107, 372; C. A. Podlasek, W. A. Stripe, I. Carmichael, M. Shang, B. Basu, A. S. Serianni, J. Am. Chem. Soc., 1996, 118, 1413.

19 J. B. Houseknecht, T. L. Lowary, C. M. Hadad, J. Phys. Chem. A, 2003, 107, 5763.

20 M. Saunders, K. N. Houk, Y.-D. Wu, W. C. Still, M. Lipton, G. Chang, W. C. Guida, J. Am. Chem. Soc., 1990, 112, 1419; G. M. Keresu, I. Kolossváry, J. Am. Chem. Soc., 2001, 123, 12708.

21 W. Gordy, R. L. Cook, Microwave Molecular Spectra; New York: Wiley; 1984; D. G. Lister, J. N. MacDonald, N. L. Owen, Internal Rotation and Inversion: An Introduction to Large Amplitude Motions in Molecules; New York: Academic Press; 1978.

22 J. K. G. Watson, Vibrational Spectra and Structure; J. R. Durig, Ed.; Elsevier: Amsterdam, 1977; pp. 1-89.

23 R. C. Woods, J. Mol. Spectrosc., 1967, 22, 49; J. M. Vacherand, B. P. van Eijck, J. Burie, J. Demaison, J. Mol. Spectrosc., 1986, 118, 355.

24 R. Meyer, J. C. López, J. L. Alonso, S. Melandri, P. G. Favero, W. Caminati, J. Chem. Phys., 1999, 111, 7871.

25 J. Raap, J. H. van Boom, H. C. van Lieshout, C. A. G. Haasnoot, J. Am. Chem. Soc., 1988, 110, 2736. 